\title{
A Reference Model for the Information-Based Support of Enterprise Transformations
}

\author{
Nils Labusch, Stephan Aier, Robert Winter \\ Institute of Information Management, University of St.Gallen, \\ St.Gallen, Switzerland \\ \{Nils.Labusch, Stephan.Aier, Robert.Winter\}@unisg.ch
}

\begin{abstract}
Enterprises from time to time have to go through radical changes, oftentimes referred to as enterprise transformations (ETs). Depending on the type of ET that is conducted, different information requirements exist. In order to support ETs, a reference information model should therefore distinguish different ET types. Based on the empirical analysis of ETs that is used to determine four ET types with different information requirements, we construct such a reference model in the paper at hand. The application of the model is exemplified with the case of enterprise architecture management as an information provider.
\end{abstract}

Keywords: enterprise transformation, information model, enterprise architecture management

\section{Introduction}

Enterprises from time to time have to go through changes that are not routine but fundamental and radical. These changes are designated as enterprise transformations (ETs) [1]. ETs substantially alter an organization's relationships with its key constituencies like customers or suppliers [1]. Examples of such fundamental changes are adaptions of the business model [2], mergers and acquisitions [3], or introductions and replacements of enterprise-wide information technology $[4,5,6]$. Conducting ETs is challenging and many efforts fail $[5,7]$. ETs are also discussed under the terms "business transformation" $[8,9,10,11]$ or "organizational transformation" $[6,12,13$, 14].

Research concerning ETs is conducted since decades in different research disciplines; including information systems (IS) research. However, Besson \& Rowe [15] conclude that past and current work mostly focusses on psychological and sociocognitive inertia (e.g., employee resistance) - socio-technical and economic inertia are underestimated, or seem to be overlooked in ET research. We thus consider ETs a topic that offers huge research potentials for IS researchers due to the holistic perspective that IS can offer about people, tasks, and technology. Supporting ET managers with this perspective also provides significant potentials for practice.

During an ET, many stakeholders are involved which have extensive and diverse information requirements. These oftentimes need to be fulfilled by ET managers (e.g., 
program managers, C-level executives). Providing decision relevant information for an ET is a mission critical task [16] and the availability of information at the right time to monitor and troubleshot the ET is described as a major success factor [17].

ET information requirements can be met by sourcing and integrating information from many different information systems. Since ETs affect the entire enterprise, the most important information is usually sourced from enterprise-wide information systems like transactional (ERP) systems, data warehouses, function-specific information systems (e.g., Human Relations), or project/program management IS. Important sources of information are systems that are already build to support enterprise-wide coordination - like, e.g., Enterprise Architecture Management (EAM) information systems. In order to utilize these systems in an ET, an information reference model would be helpful, that allows identifying the relevant information requirements.

However, depending on their drivers, their criticality, affected functions, and other contingencies, ETs are very different. As a consequence, the information requirements of ETs are different. Therefore we need to understand the different types of ET from an information perspective in order to provide appropriate and tailored information support. Our goal therefore is not to propose a 'one size fits all' information reference model for ET support, but instead to leverage the knowledge prevalent in design science research to construct a reference information model that allows distinguishing different ET types. Thus, we pose the following research question:

RQ: How can information requirements in ETs be structured in a reference information model that allows distinguishing different ET types?

We proceed as follows: We discuss related work in section two. We go on with introducing our research and design approach. We present results from the classification process of ETs from an information requirements perspective in section four. A demonstration based on EAM as an information provider is presented in section five. The paper is concluded with a summary and limitations in section six.

\section{Related Work}

In academic research, typically two understandings of change are prevalent [18]: On the one hand, evolutionary views assume that organizational change is incremental and continuous. Fundamental differences result from the accumulation of small changes over long periods. On the other hand, punctuated equilibrium models [19] assume that fundamental organizational change occurs in short periods of discontinuous, revolutionary change, which punctuate long eras of relative stability represented by incremental, convergent changes [14].

ET research is rooted in the latter research stream. Examples of such fundamental changes are ETs of the business model [2], mergers \& acquisitions [3], or introductions and replacements of enterprise-wide IT systems $[4,5,6]$. Especially because of the latter example and the assumed potential of IT to impose ETs [20], the topic gains attention in the IS community [e.g., 21, 22]. 
When transforming an enterprise, a high number of decisions, some of them with major consequences, have to be taken. In order to take these decisions on a thorough foundation, manifold information has to be collected and consolidated in short time $[23,24,25,26]$. Thus, a fit between the information requirements and the information provision is crucial $[16,27,28,29]$.

However, what is missing in order to take appropriate design decisions for the information provision are details about the information needed most. Thus, a classification is valuable that allows distinguishing different types of ETs and explicates the occurring information demands. While very few classifications exist in order to distinguish ETs [e.g., 1], none of them classifies ETs from an information requirements perspective. We aim at closing these gaps by understanding, which types of ET exist from an information requirements perspective and providing an information reference model for ETs.

Reference models are well-known in IS research. Such a model is considered to be a conceptual framework that can be used as a draft for IS design and development [30]. Reference models exist for different areas, e.g., logistics [31] or quality management [32]. In order to be useful, reference models need to be adaptable to certain situations in an efficient manner and thus need to provide guidance on their adaption [33]. We aim at integrating the determined ET types in order to simplify the adaption and configuration of the proposed model.

\section{Research Approach}

Existing classifications of ETs focus on the respective goals, not on information requirements. However, to allow for a tailoring of information systems concerning the information requirements of an ET, we need a classification that is based on these requirements (and not, e.g., the ET goals). In order to derive such a classification and to identify ET types based on the information requirements, we base our research process on the guidance given by Winter [34] and Bucher \& Klesse [35].

\subsection{Identification of Contingency Factors and Information Requirements}

In order to understand the diversity of ETs, we need to identify relevant contingency factors and information requirements. Basically, these are differentiated into three groups: the environment of the ET ("the organization"), the ET itself (goals, reasons, figures, etc.) and the information requirements of ET managers.

In order to identify contingency factors concerning the ET and the organization, we conducted a literature survey in databases (EBSCO and ISI) and top journals of information systems and management science. We followed the Basket of Eight [36] (eight journals) and the European JOURQUAL ranking [37] (journals ranked equal or higher than $\mathrm{B}$ in the partial rankings information systems (26 journals) and management (21 journals)). We applied the search term "(((organizational OR enterprise OR business OR radical) AND transformation) OR "radical change")" in the title in combination with the term "(type* OR archetype* OR class* OR categor* OR taxonom* 
OR segment* OR dimension*)“ in the abstract. The search revealed 397 results in total, after reviewing the abstracts; we considered 23 papers relevant for further analysis. We further included sources from forward and backward analysis. We surveyed these sources (mostly empirical studies or cases) in detail, in order to extract concrete contingency factors for the analysis. Examples are goals of the ET [38], affected departments [39], reasons for the ET [14], and figures like the involved resources [e.g. 40].

In order to analyze the information requirements during ETs, we incorporate work that we conducted earlier. In two papers we identified information needs that ET managers potentially would have. One study is based on literature [41] the other on interviews with experts [42]. We consolidate the identified information items from the studies above in one list (see the provided information model in figure 2 for details) with different groups of information and the single information requirements. This list is provided to the ET experts as part of the study. The goal is to identify, whether all of these information requirements were existing during all ETs, or if differences could be identified.

\subsection{Empirical Analysis}

We provided the contingency factors and information objects to four practitioners in one organization in order to evaluate if they were comprehensible and if major aspects were missing. The participants had different job positions that deal with ETs (e.g., project managers, process manager). We wanted to make sure that the contingency factors and information objects are unambiguous and can be judged in reasonable time. During this pilot phase we noticed that filling in the questionnaire takes about 30 minutes. Due to the complexity of the problem domain we consider this amount of time reasonable.

During the pilot phase some information objects needed to be rephrased to increase their clearness and to preserve the meanings from the source papers. In addition, this pretest was meant to identify further contingency factors or information objects that we would need to add. Interestingly, no more factors were added by the experts, which might serve as a quality indicator for the ones we originally choose.

After the pre-test, we provided the questionnaire to a total of 30 highly knowledgeable informants that are able to describe ETs as the unit of analysis. These were for example ET managers, CEOs, or program managers. The informants were asked to rate the items based on a five point Likert scale [43]. We were able to collect data from a variety of industries (see table 1, multiple answers allowed). We consider including multiple industries an advantage due to avoiding industry-specific bias and thus increasing the general applicability of the artifact. 
Table 1. Overview of participating industries

\begin{tabular}{lc}
\hline Industry & Amount \\
\hline Education & 1 \\
\hline Power Supply & 7 \\
\hline Financial Services & 6 \\
\hline Healthcare & 3 \\
\hline Information \& Communication & 8 \\
\hline Production & 4 \\
\hline Transport \& Logistics & 1 \\
\hline Insurance & 2 \\
\hline Other & 3
\end{tabular}

\section{$4 \quad$ Design Process}

\subsection{Identification of Enterprise Transformation Types}

We conducted a hierarchical cluster analysis (Ward's method, squared Euclidian distance) based on the information requirements illustrated above (see the concrete information items in Fig 2.). In order to use as many cases as possible for the analysis, we handled missing values by replacing the missing with column (variable) means. If more than $10 \%$ of values were missing, we omitted the case. This procedure left us with 21 ETs that were used for the cluster analysis.

An important challenge when designing a reference model is to determine the number of configurations it supports. Whenever too many configurations exist, the number of organizations decreases were a particular configuration can be applied. A 'one size fits all' model or a model that supports too few configurations, on the other hand, is not considered to be useful because specific requirements cannot be met to a sufficient extent $[44,45]$. We determined the number of configurations for our model based on the goal to provide meaningful guidance for the ET support but at the same time adhere to statistical criteria.

A two cluster solution would have been most appropriate concerning the cluster distance (measured by the squared Euclidian distance). However, with this configuration, cluster one would contain two cases while the second cluster would contain the others. With a three cluster solution, clusters would not be a helpful foundation for design since differences of information requirements among the clusters were not concise. In the four cluster solution, clusters are more differentiated concerning their information requirements and hence provide more appropriate guidance for the design step. Five or six cluster solutions do not provide enough differences to warrant another differentiation in the following model design. In consequence, we choose a four 
cluster solution to guide the following design steps. Figure 1 provides an overview of the summarized mean values in the respective groups of information.

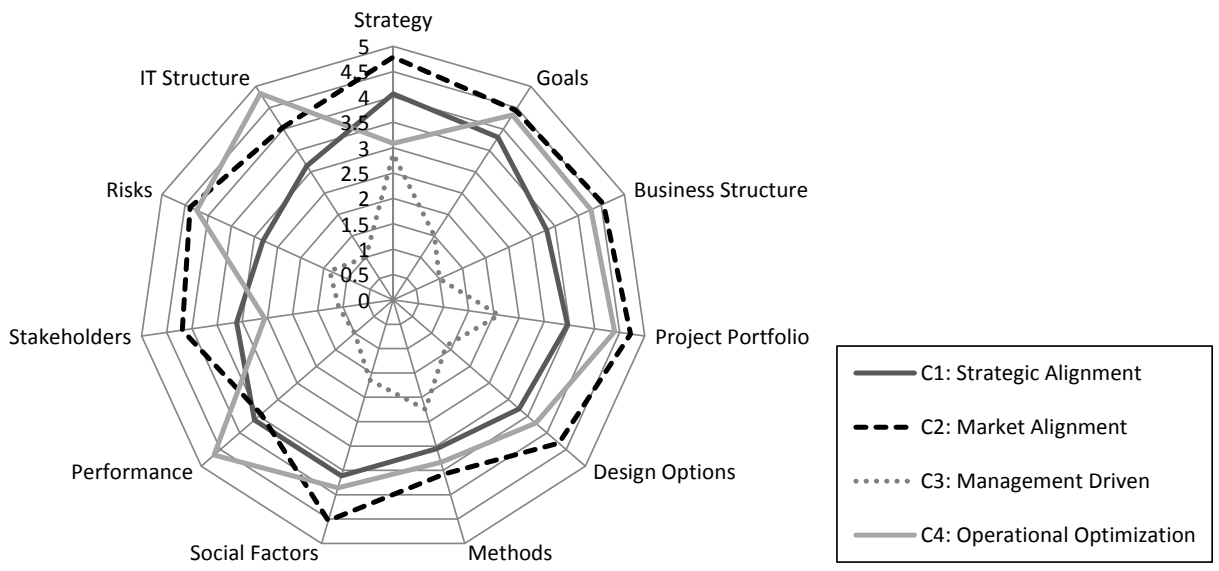

Fig. 1. Information demands in the different clusters

Cluster one, strategic alignment, represents ETs that are driven by strategic changes or the introduction of new products and necessary changes in the IT. Corporate management, but also IT departments guide these ETs. The strongest goal is optimization (thus, achieving more efficiency, e.g., in processes or IT systems). A second goal is increasing the flexibility of the company (thus, being able to react to future changes in the market environment). Information that was considered most important in this cluster is related to strategy (e.g., business strategy, ET drivers) or goals (e.g., goal descriptions). Information that was considered least important is about locations, information relevant to outsourcing, information about affected stakeholders. Furthermore, information about shareholders, suppliers, internal guidelines, and IT security were of least importance. The average level of information considered necessary, is rather in the middle (compared to the other clusters).

Cluster two, market alignment ETs, represents ETs that are driven by the introduction of new products and services or by changes of the addressed market segments. ETs are guided by corporate management and marketing departments. It seems to be consequent that goals of these ETs are mostly repositioning in the market and optimization of internal structures. Thus, in this cluster, the changes in the market environment already happened and triggered a respective reaction by the organization. On average, the information requirement in cluster two is higher than in the first one. Information that is considered to be important in this cluster is similar to the strategic alignment cluster concerning the top-most important ones - especially concerning strategy and goals. However, some information is important that is highly related to the cluster-specific goals, e.g., skills of employees, product portfolio, legislative rules, customers, etc. Less important information is about benefits, current costs as much as quantitative and qualitative monitoring of the success. 
Cluster three, management-driven ETs, represents ETs that are driven by changes in corporate management and changes of the company structure. They are guided by corporate management. The strongest goal is repositioning. For this kind of ETs the market environment, an overview of projects, redundancies between those projects, etc. were considerably important. However, most values about the importance of the information are very small compared to the other clusters and the overall average of the dataset. ETs in this cluster do not need much information because they are conducted by managers that rely solely on their experience implementing their vision about the organization. Thus, from an information perspective, the support in this cluster can only occur on a very low level.

The ETs represented by cluster four, operational optimizations are driven by changes of the environment (e.g., legal-wise) and by necessary adaptations of supporting IT systems. Additional drivers are performance crises or structural changes in the company. It is not surprising that such ETs are guided by the technology/IT departments and the corporate management. The main goal is optimization, partially also repositioning. Most important information that is specific in this cluster is about applications, IT infrastructure, redundancies between projects, capabilities of employees, processes, etc. What are considered least important information are ET drivers, market environment, and most information about external stakeholders. Thus, the ETs that are described in this cluster are mostly internally visible and external impact is less considered.

Based on the findings from literature and the empirical analysis, we are able to design a reference model that consolidates these findings.

\subsection{Design of an Enterprise Transformation Information Model}

We used the clusters above, in order to provide guidance, which information are most considerable in which ET type. We found the median to be an appropriate decision criterion due to its stability concerning outliers. When the information item was rated with the median value itself, it was included in the ET type. Thus, the model below (figure 2) allows for configuration of information systems concerning the four differentiated ET types. This allows for a much more efficient application of the model depending on the ET type, the organization has to conduct.

The model is comprised of eleven information groups that contain more detailed information items. For each information item an indicator label is assigned that provides configuration guidance. Each ET is supposed to mostly belong to one of the clusters introduced above. Once the ET type is determined, the indicator color next to the information item provides guidance about the relevance of the information item for this specific ET type. When the indicator is colored white, the information item is not relevant for the corresponding cluster. Consider for example the information item "important steps" in the "strategy" information group. It is relevant for all types of ET, except the management-driven (Cluster 3) ones. 


\begin{tabular}{|l|c|c|c|}
\hline Strategy \\
\begin{tabular}{|c|c|c|}
\hline $\begin{array}{c}\text { Important steps } \\
\text { (e.g. roadmap) }\end{array}$ & $\mathrm{T}^{\mathrm{T}}$ & $\mathrm{T} 2$ \\
\hline T3 & $\mathrm{T} 4$ \\
\hline Market situation & $\mathrm{T} 1$ & $\mathrm{~T} 2$ \\
\hline Drivers & $\mathrm{T} 3$ & $\mathrm{~T} 4$ \\
\hline Business Strategy & $\mathrm{T} 1$ & $\mathrm{~T} 2$ \\
\hline & $\mathrm{T} 3$ & $\mathrm{~T} 1$ \\
\hline & $\mathrm{T} 3$ & $\mathrm{~T} 2$ \\
\hline & & \\
\hline
\end{tabular} \\
\hline
\end{tabular}
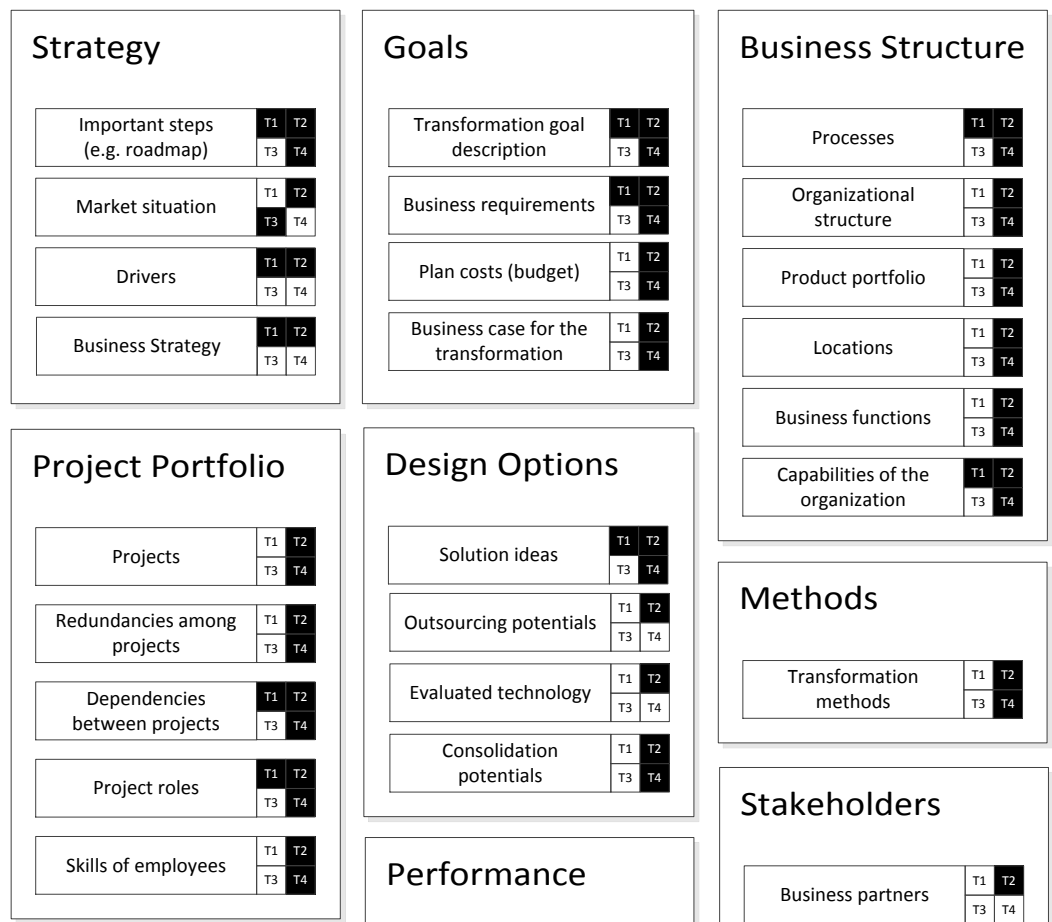

\section{Design Options}
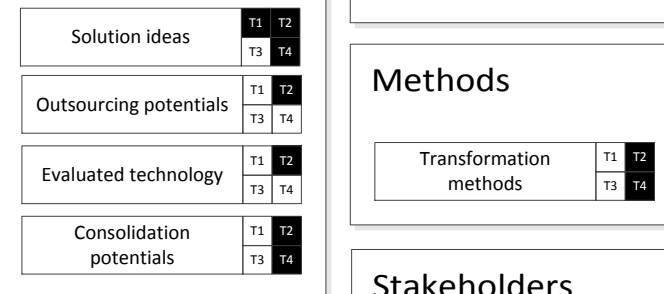

\section{Stakeholders}
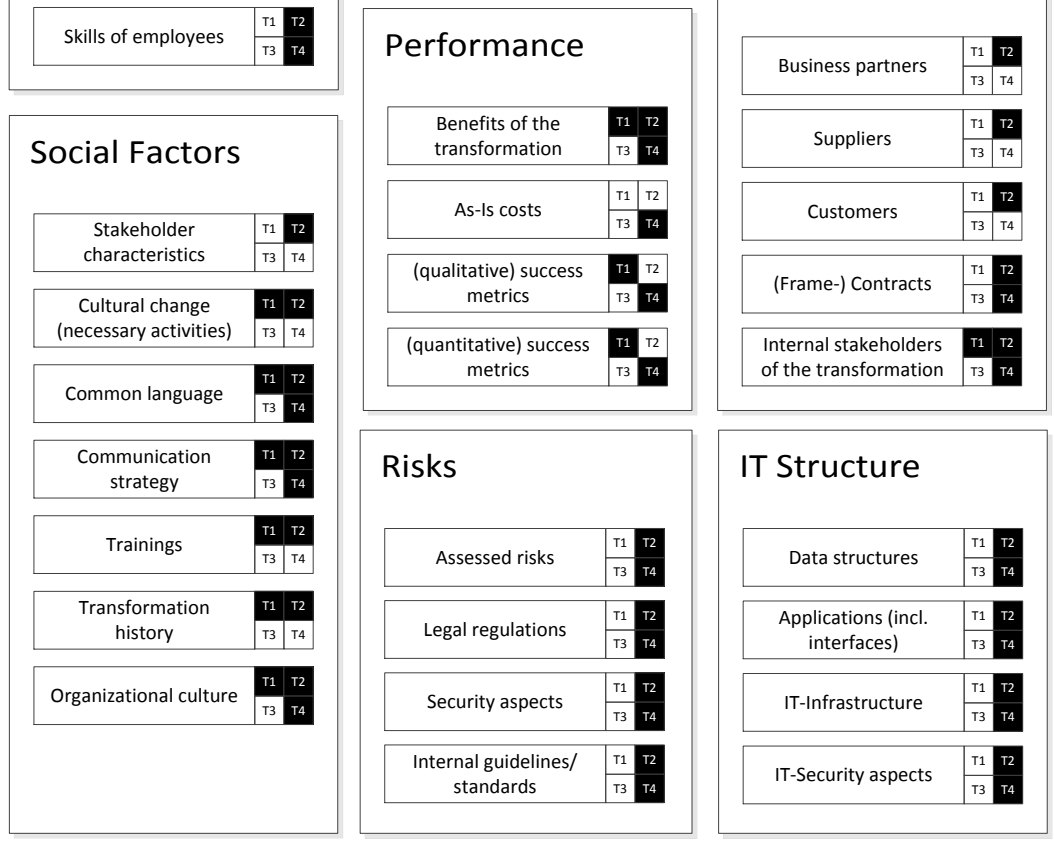

Information important for this type

T1: Strategic ALignment

T3: Management Driven

T4: Operational Optimization

Fig. 2. ET reference information model 
Due to the level of abstraction in the model, we do not provide detailed relations between the information groups, since information needs to be combined and exchanged in many ways that are depending on the concrete ET in the concrete organization. In very broad terms, the information groups relate together as follows: In order to prepare a sufficient strategy for the ET, the transformation's most important steps, its market environment, its drivers, and the business strategy are needed to be known. Based on the ET strategy, ET managers need to determine the goals of the ET. Strategy and goals of the ET define how the ET changes business and IT structures. Based on the goals, strategy, and existing structures, different design options can be proposed and evaluated. Operationally, the ET has to be broken down in projects and project portfolios that leverage the available skills and resources. During the ET, the performance needs to be monitored. Different stakeholders that are involved in the ET need to be known and addressed. They impose social factors that heavily influence the ET. In order to ensure the success of the ET, risks need to be assessed and handled. All of the above aspects can be improved by applying methods that are designed in order to support ETs.

In concrete ETs, however, organizations need to further discuss and evaluate the model concerning their particular ET. In addition, organizations need to determine, which departments, disciplines, or information systems can provide which information that is considered to be necessary. On the other hand, designers of, e.g., information systems can use the model to analyze, in which ETs their system could be applied and add value. We use the IS enterprise architecture management (EAM) in order to demonstrate its role for the information supply in different ETs in the next section.

\section{Demonstration: EAM as a Configurable Information Provider for Enterprise Transformations}

In this section, we demonstrate, how the model designed before can be used in order to determine, if an IS could be used to support an ET. Further, we demonstrate how it can contribute to the information provision. We take EAM as an example for an IS artifact that can be tailored concerning different ET information requirements.

Enterprise architecture (EA) as such is understood as (1) the fundamental structure of a government agency or a corporation, either as a whole, or together with partners, suppliers, and/or customers as well as (2) the principles governing its design and evolution [46, 47]. Enterprise architecture management (EAM) is concerned with the establishment and continuous development of EA in order to consistently respond to business and IT goals, opportunities, and necessities [48].

Since ETs occur, when the deep structure of an organization is changed [15], the relation between the two disciplines becomes obvious: enterprise transformation means to change the structures of the enterprise, while EAM can provide information about these structures [49]. In general, huge potential is seen for EAM to support ETs [50]. 
We took the information objects presented in the model above and evaluated, if they can be provided solely by EAM, partially by EAM, or not at all by EAM. We applied a five point-Likert-Scale in order to rate the support based on the content meta-model of the Open Group Architecture Framework (TOGAF) [46] and additional literature sources (see [41] for more details about the rating procedure and the used literature). See Table 1 for the results of the analysis concerning the general EAM support of ETs.

Table 2. EAM support of ETs

\begin{tabular}{ll}
\hline Information & EAM Support \\
\hline Strategy & $\begin{array}{l}\text { Support differs, business strategy and drivers could be provided very } \\
\text { appropriately, market situation rather partially, important steps (e.g. } \\
\text { in terms of a roadmap) could be provided very well. }\end{array}$ \\
\hline Goals & $\begin{array}{l}\text { Goals and requirements are direct meta-model elements of EAM, } \\
\text { information to determine budgets and develop business cases could } \\
\text { be partially provided. }\end{array}$ \\
\hline Business & $\begin{array}{l}\text { Knowledge about structures is often considered the core of EAM, } \\
\text { thus these are all direct part of the content meta-model and the sup- } \\
\text { port is very strong. }\end{array}$ \\
\hline Project Portfolio & $\begin{array}{l}\text { Information about projects and skills are also considered core of } \\
\text { EAM. }\end{array}$ \\
\hline Design Options & $\begin{array}{l}\text { EAM can partially contribute in providing design options, however, } \\
\text { many more stakeholders need to be involved. }\end{array}$ \\
\hline Methods & $\begin{array}{l}\text { The content meta-model does not consider ET methods, minor sup- } \\
\text { port could be possible since architects are often keen on methods. }\end{array}$ \\
\hline Social Factors & $\begin{array}{l}\text { Social factors are usually not contributed by EAM. Establishing and } \\
\text { designing a common language is part of EAM. }\end{array}$ \\
\hline Performance & $\begin{array}{l}\text { EAM is able to collect benefits of ETs and additional qualitative } \\
\text { measures. Financial side is out of EAM scope. }\end{array}$ \\
\hline Stakeholders & $\begin{array}{l}\text { Concerning Stakeholders, EAM is able to provide information about } \\
\text { contracts, suppliers and internal stakeholders of the ET since these } \\
\text { are content meta-model elements. }\end{array}$ \\
\hline Guidelines/standards can be provided. \\
\hline Providing Information about IT structures is core of EAM.
\end{tabular}

Based on the table above and the ET information model, we can distinguish the EAM support for the different ET types.

ETs of the type "strategic alignment" is only partially be supported by EAM. The required information in terms of strategy and goals can be provided very well. Information about business structure, project portfolio and IT structures are in general not strongly requested within this ET type. Thus, lots of the information that EAM could 
provide would not be necessary for this type. The EAM support thus would be much focused (e.g., on business requirements, processes, or capabilities).

The ET type "market alignment" is much stronger supported. In these ETs the enterprise needs to be realigned with the market, thus, plenty of information about the current structures is needed. This information can be very well provided by EAM. Since these ETs occur very sudden, the information needs to be available quickly thus, it is very valuable if it is already documented. In consequence, EAM can provide information about strategy, goals, business structures, IT structures as much as the project portfolio and further ones. Of course, the necessary information could neither exclusively nor completely be provided by EAM - when it comes to stakeholder or social factor related information, EAM can only provide minor support.

The ET type "management driven" is almost not supported by EAM. The only information that can be provided is about the market situation. Since this information can anyway only partially be provided by EAM, the model shows that EAM is not the preferred discipline/information system to support the ET type.

For "operational optimizations" EAM again can provide valuable information. According to the model, strategic aspects are almost not important and ETs of this type rather require fundamental knowledge about the business and IT structure of the company in order to realize optimizations. Thus, these ETs directly address again the core of EAM.

Figure 3 illustrated the summary of the EAM system support differentiated by ET type. 
Type 1:

Strategic

Alignment
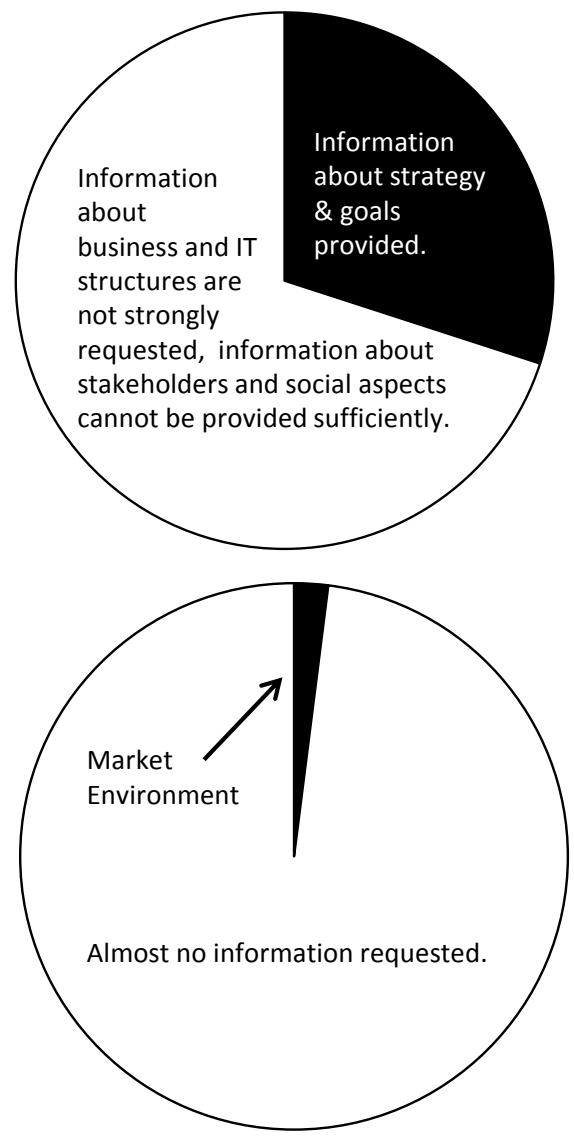

Type 3:

Management

Driven
Type 2:

Market

Alignment
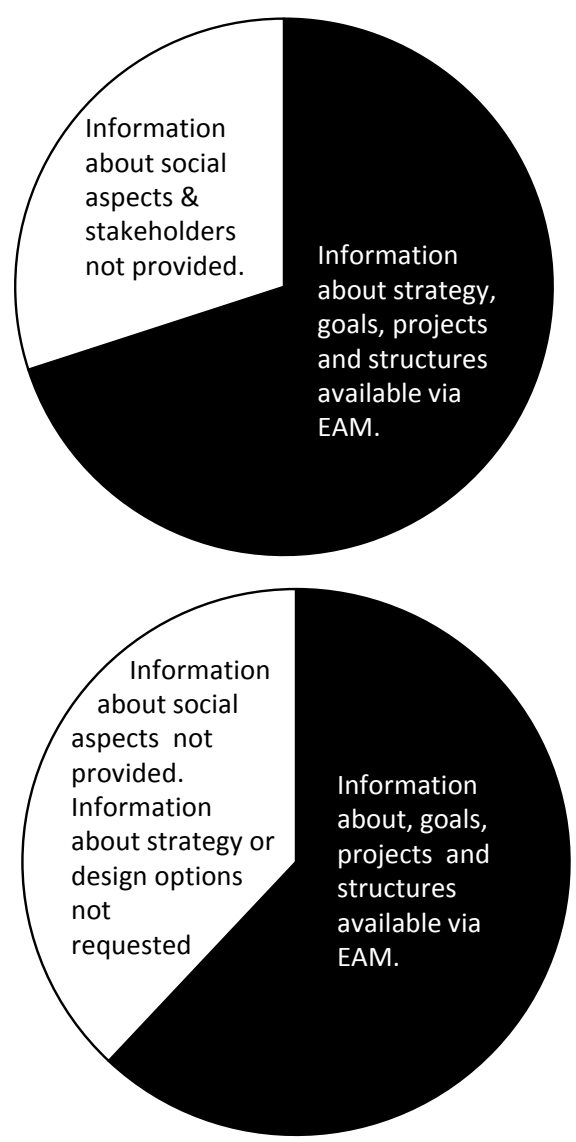

Type 4:

Operational

Optimization

Fig. 3. EAM system support differentiated by ET type

\section{Summary, Limitations \& Outlook}

In the paper at hand we provide a reference information model that allows distinguishing different types of ETs based on the information that ET managers require. The model distinguishes four different ET types that have been identified with an empirical analysis of ETs. Based on the model, we demonstrate how the information provision by EAM needs to be configured, in order to fulfill ET-type dependent in- 
formation requirements. The demonstration shows that certain types of ET can be much better supported by IS than others. Our contribution to the body of ET literature therefore is a model that allows for providing information during ETs much more focused. Further, the model provides a dense overview of information that is necessary in ETs.

In order to identify, how the best information support for the identified ET types can be assured, the demonstration that we conducted should be repeated with other information systems beyond EAM. Candidates are ERP systems, business intelligence systems, or other enterprise-wide IS.

Some limitations occur in the presented research. It could be the case that further clusters exist that we did not identify due to a limited amount of transformation cases. This problem occurs whenever complex real-world phenomena are researched and abstracted in a model. Future work and an increased empirical foundation of the model will show, if the identified types need to be revised or if they will be confirmed. Due to the highly knowledgeable informants that we collected the responses from, we are reasonably confident to assume the latter. Further, each ET in the evaluated set of data is described by one respondent. Due to the manifold roles that conduct ET management (e.g., program managers, C-level executives), role-specific differences about required information could occur. Based on the current amount of data collected, we are not able to account for these differences. However, such different information requirements by different roles provide an interesting field for future research.

Additional future work planned in the project is to provide the model to practitioners that deal with EAM during ETs. Focus groups or interviews with these experts will provide valuable feedback and input to the model in order to further increase its applicability and utility, especially in the domain of EAM. We invite researches that primarily deal with other IS to extent and apply the model in their domains.

\section{Acknowledgement}

This work has been funded by the Swiss National Science Foundation (SNSF).

\section{$7 \quad$ References}

1. Rouse, W.B.: A Theory of Enterprise Transformation. Systems Engineering 8:4, 279-295 (2005)

2. Aspara, J., Lamberg, J.-A., Laukia, A., Tikkanen, H.: Strategic management of business model transformation: lessons from Nokia. Management Decision 49:4, 622-647 (2011)

3. Johnston, J., Madura, J.: Valuing the Potential Transformation of Banks into Financial Service Conglomerates: Evidence from the Citigroup Merger. The Financial Review 35:2, 17-36 (2000)

4. Bhattacharya, P.J., Seddon, P.B., and Scheepers, R.: Enabling Strategic Transformations with Enterprise Systems: Beyond Operational Efficiency. In: ICIS 2010 Proceedings, p. Paper 55 (2010)

5. Sarker, S., Lee, A.S.: IT-enabled organizational transformation: a case study of BPR failure at TELECO. The Journal of Strategic Information Systems 8:1, 83-103 (1999) 
6. Hock-Hai Teo, B., Tan, C.Y., Wei, K.-K.: Organizational Transformation Using Electronic Data Interchange: The Case of TradeNet in Singapore. Journal Of Management Information Systems 13:4, 139-165 (1997)

7. Kotter, J.P.: Leading Change: Why Transformation Efforts Fail. Harvard Business Review 73:2, 59-67 (1995)

8. Ashurst, C., Hodges, J.: Exploring Business Transformation: The Challenges of Developing a Bene $\square$ ts Realization Capability. Journal of Change Management 10:2, 217237 (2010)

9. Ash, C.G., Burn, J.M.: Assessing the benefits from e-business transformation through effective enterprise management. European Journal Of Information Systems 12, 297-308 (2003)

10. Daniel, E.M., Wilson, H.N.: The role of dynamic capabilities in e-business transformation. European Journal Of Information Systems 12, 282-296 (2003)

11. Davidson, W.H.: Beyond Re-Engineering: The Three Phases of Business Transformation. IBM Systems Journal 32:1, 65-79 (1993)

12. Dixon, S.E.A., Meyer, K.E., Day, M.: Stages of Organizational Transformation in Transition Economies: A Dynamic Capabilities Approach. Journal Of Management Studies 47:3, 416-436 (2010)

13. Orlikowski, W.J.: Improvising Organizational Transformation Over Time: A Situated Change Perspective. Information Systems Research 7:1, 63-92 (1996)

14. Romanelli, E., Tushman, M.L.: Organizational Transformation as Punctuated Equilibrium: An Empirical Test. Academy Of Management Journal 37:5, 1141-1166 (1994)

15. Besson, P., Rowe, F.: Strategizing information systems-enabled organizational transformation: A transdisciplinary review and new directions. Journal Of Strategic Information Systems 21:2, 103-124 (2012)

16. Galbraith, J.R.: Organization Design: An Information Processing View. Interfaces 4:3, 2836 (1974)

17. Keller, S., Meaney, M., Pung, C.: McKinsey Global Survey results: What successful transformations share. (2010)

18. Wischnevsky, J.D., Damanpour, F.: Punctuated Equilibrium Model of Organizational Transformation: Sources and Consequences in the Banking Industry. Research In Organizational Change And Development 15, 207-239 (2005)

19. Gersick, C.J.G.: Revolutionary Change Theories: A Multilevel Exploration of the Punctuated Equilibrium Paradigm. Academy Of Management Review 16:1, 10-36 (1991)

20. Cooper, R.B.: Information technology development creativity: a case study of attempted radical change. MIS Quarterly 24:2, 245-276 (2000)

21. Thorogood, A., Reynolds, P., Yetton, P.: Performing Under Pressure: IT Execution in a \$1.4bn Business Transformation. In: ICIS 2010 Proceedings, p. Paper 164 (2010)

22. Sammon, D., Adam, F.: Justifying an ERP Investment: Critical Success Factors for Transformation Investments. In: ICIS 2008 Proceedings, p. Paper 60 (2008)

23. Tichy, N.M.: Managing Organizational Transformations. Human Resource Management 22:1-2, 45-60 (1983)

24. Fry, L.W., Vitucci, S., Cedillo, M.: Spiritual leadership and army transformation: Theory, measurement, and establishing a baseline. The Leadership Quarterly 16, 835-862 (2005)

25. Singh, R., Mathiassen, L., Stachura, M.E., Astapova, E.V.: Dynamic Capabilities in Home Health: IT-Enabled Transformation of Post-Acute Care. ournal of the Association for Information Systems 12:2, Article 2 (2011)

26. Klein, A., Krcmar, H.: DCXNET: E-Transformation at DaimlerChrysler. In: ICIS 2003 Proceedings, p. Paper 103 (2003) 
27. Galbraith, J.R.: Designing Organizations: An Excecutive Guide to Strategy, Structure, and Process. Jossey-Bass, San Francisco (2002)

28. Galbraith, J.R.: Designing Complex Organizations. Addison-Wesley, Boston, MA (1973)

29. Galbraith, J.R.: Organization Design. Addison-Wesley, Reading, MA (1977)

30. Fettke, P., Loos, P.: Perspectives on Reference Modeling. In: Fettke, P., Loos, P. (eds.): Reference Modeling for Business Systems Analysis, pp. 1-20. Idea Group Publishing, Hershey, PA and London (2007)

31. Holten, R., Melchert, F.: Das Supply Chain Operations Reference (SCOR)-Modell. In: Becker, J., Knackstedt, R. (eds.): Wissensmanagement mit Referenzmodellen. Konzepte für die Anwendungssystem- und Organisationsgestaltung, pp. 207-226. Physica, Heidelberg (2002)

32. European Foundation for Quality, M.: The EFQM Excellence Modell. EFQM Representative Office, Brüssel (1999)

33. Becker, J., Delfmann, P., Knackstedt, R.: Adaptive Reference Modeling: Integrating Configurative and Generic Adaptation Techniques for Information Models. In: Becker, J., Delfmann, P. (eds.): Reference Modeling, pp. 27-58. Physica, Heidelberg (2007)

34. Winter, R.: Problem Analysis for Situational Artefact Construction in Information Systems. In: Carugati, A., Rossignoli, C. (eds.): Emerging Themes in Information Systems and Organization Studies, pp. 97-113. Physica, Heidelberg (2011)

35. Bucher, T., Klesse, M., Kurpjuweit, S., Winter, R.: Situational Method Engineering - On the Differentiation of "Context" and "Project Type". In: Situational Method Engineering Fundamentals and Experiences, pp. 33-48. Springer, Geneva (2007)

36. Association for Information, S.: Senior Scholars' Basket of Journals. Springer, Heidelberg (2010)

37. Schrader, U., Hennig-Thurau, T.: VHB-JOURQUAL2: Method, Results, and Implications of the German Academic Association for Business Research's Journal Ranking. BuR Business Research 2:2, 180-204 (2009)

38. Baumöl, U.: Strategic Agility through Situational Method Construction. In: Proceedings of the European Academy of Management Annual Conference 2005, München (2005)

39. Porter, M.E.: Competitive Advantage: Creating and Sustaining Superior Performance. Free Press, New York (1985)

40. eurostat (ed.): NACE Rev. 2 Statistical classification of economic activities in the European Community, Luxembourg (2008)

41. Labusch, N., Winter, R.: Towards a Conceptualization of Architectural Support for Enterprise Transformation. In: Proceedings of the European Conference on Information Systems (ECIS) 2013, Utrecht, NL (2013)

42. Labusch, N., Aier, S., Rothenberger, M., Winter, R.: Architectural Support of Enterprise Transformations: Insights from Corporate Practice. In: Tagungsband Multikonferenz Wirtschaftsinformatik 2014, pp. 1048-1060. Universität Paderborn, Paderborn (2014)

43. Likert, R.: A Technique for the Measurement of Attitudes. Archives of Psychology 22:140, 1-55 (1932)

44. vom Brocke, J., Thomas, O.: Designing Infrastructures for Reusing Conceptual Models - A General Framework and its Application for Collaborative Reference Modeling. In: Proceedings of the Ninth International Conference on Business Information Systems (BIS'06), Klagenfurt, Austria (2006)

45. Becker, J., Delfmann, P., Knackstedt, R., Kuropka, D.: Konfigurative Referenzmodellierung. In: Becker, J., Knackstedt, R. (eds.): Wissensmanagement mit Referenzmodellen. Konzepte für die Anwendungssystem- und Organisationsgestaltung, pp. 25-144. Physica, Heidelberg (2002) 
46. The Open Group: TOGAF Version 9.1 (2011)

47. Winter, R., Fischer, R.: Essential Layers, Artifacts, and Dependencies of Enterprise Architecture. Journal of Enterprise Architecture 3:2, 7-18 (2007)

48. Aier, S., Gleichauf, B., Winter, R.: Understanding Enterprise Architecture Management Design - An Empirical Analysis. In: Proceedings of the 10th International Conference on Wirtschaftsinformatik WI 2.011, pp. 645-654, Zurich (2011)

49. Gardner, D., Fehskens, L., Naidu, M., Rouse, W.B., Ross, J.: Point-Counterpoint: Enterprise Architecture and Enterprise Transformation as Related but Distinct Concepts. Journal of Enterprise Transformation 2:4, 283-294 (2012)

50. Winter, R., Townson, S., Uhl, A., Labusch, N., Noack, J.: Enterprise Architecture and Business Transformation: The Difference and Synergy Potential. $360^{\circ}-$ The Business Transformation Journal, (2012) 